\title{
"Memento lues, delenda lues!" A profilaxia e o tratamento da sífilis na Revista de Medicina nos anos 1920
}

\author{
"Memento lues, delenda lues!" Prophylaxis and treatment of \\ syphilis in the Revista de Medicina in the 1920s
}

Priscila Bermudes Peixoto*

Leonardo Dallacqua de Carvalho*

\begin{abstract}
RESUMO: O objetivo deste trabalho consiste em analisar as abordagens sobre a sífilis encontradas na Revista de Medicina, com ênfase em refletir sobre o modo como esta enfermidade era pensada no contexto dos anos 1920, momento em que a corrente higienista possuía considerável adesão entre os médicos brasileiros. Entendida como um fator de degeneração, a sífilis era mencionada como consequência de um comportamento impróprio e imoral. Nesse sentido, objetivamos analisar as discussões em torno de seus tratamentos e medidas profiláticas.
\end{abstract}

Palavras-chave: Sífilis, Medicina, Higienismo, Revista de Medicina.

ABSTRACT: The aim of this paper is to analyze the approaches to syphilis found in the Revista de Medicina, with an emphasis on reflecting on how this disease was thought of in the context of the 1920 s, period when the hygienist doctrine had considerable membership among Brazilian doctors. Understood as a factor of degeneration, syphilis was mentioned as a consequence of an improper and immoral behavior. Thus, we aimed to analyze the discussions around their treatments and preventive measures.

Keywords: Syphilis, Medicine, Hygienism, Revista de Medicina.

\footnotetext{
* Mestranda em História Universidade Estadual de São Paulo, Franca/SP, Brasil. Bolsista FAPESP. E-mail: priscilabermudes1@gmail.com

** Doutorando em História das Ciências e da Saúde - Fundação Instituto Oswaldo Cruz, Rio de Janeiro/RJ, Brasil. E-mail: leo.historiafiocruz@gmail.com
} 


\title{
Introducão
}

\begin{abstract}
"Memento lues" é a phrase que deve sempre sôar aos ouvidos do clinico; "delenda lues" é a tarefa momentosa do medico e do higienista. ${ }^{1}$
\end{abstract}

Com estas palavras o catedrático da Faculdade de Medicina de São Paulo, Celestino Bourroul apregoava um discurso recorrente nas primeiras décadas do século XX no Brasil, a grande preocupação com a sífilis, vista como mal social e considerada como fruto de comportamento imoral. Para os médicos higienistas não bastava curar aqueles acometidos por tal enfermidade, era preciso investir em medidas profiláticas, que acabavam, por sua vez, envolvendo mecanismos de controle social. Como afirmava Bourroul era preciso "lembrar-se" da sífilis constantemente, sendo uma doença perigosa que acarretava, supostamente, tantos outros males, os médicos não poderiam vacilar em relação à mesma. Era primordialmente necessário também "destruíla". Dado isso, pretende-se neste texto analisar a compreensão da sífilis, sobretudo na década de 1920, por meio dos artigos publicados na Revista de Medicina, trazendo uma abordagem dos modos de prevenção e de tratamento dessa doença. ${ }^{2}$

Sífilis, higienismo e medicina em São Paulo no início do século XX:

$\mathrm{Na}$ segunda metade do século XX a historiografia passou por um processo de abertura a novos campos e objetos, diversificando suas fontes e metodologias, nota-se também uma maior preocupação com os aspectos sociais e modos de sentir. A história das mentalidades, por exemplo, ia ganhando um peso cada vez maior, assim como abordagens sobre o corpo, a família, as relações entre os sexos, etc. Nesse sentido, possibilitou-se também a historiografia refletir sobre as doenças, logo, estas deixaram de ser objeto exclusivo da medicina e puderam ser problematizadas pela História ${ }^{3}$, para análise desta temática muitas vezes se faz necessário estabelecer uma relação com a História das Ciências ou a História das Ideias ${ }^{4}$. Por este motivo, ao pensarmos a trajetória da sífilis nos anos 1920 é necessário termos em vista as correntes científicas em voga neste período, uma vez que a amplitude da sífilis ganhou diversos enfoques no século XX, sendo inclusive, abordada por Ludwik Fleck na teorização dos estilos e coletivos de pensamento. ${ }^{5}$

Conforme procuraremos demonstrar neste artigo, o higienismo possuía um discurso particular em torno da sífilis, encarada como doença própria de um comportamento desregrado e imoral, que comprometia, supostamente com base na crença de sua hereditariedade, não só o próprio enfermo como também toda sua descendência. Logo, este trabalho se propõe a sondar os discursos 
médicos publicados na Revista de Medicina (São Paulo) sobre as formas de profilaxia e tratamento da sífilis, refletindo acerca da ambição médica de legitimação de suas propostas de intervenção social.

No início do século XX, São Paulo vivenciava um momento de agitação e efervescência. A cidade vinha se estabelecendo como um dos centros urbanoeconômicos mais importantes do país, fato este vinculado ao fortalecimento do setor cafeeiro que possibilitara condições para o nascimento do capital industrial. São Paulo assistia a um processo de expansão demográfica, tanto pela chegada de imigrantes, como pela formação da incipiente classe operária e o êxodo de ex-escravos. Conforme assinala Nicolau Sevcenko ${ }^{6}$, sobretudo nos anos 1920, a capital paulista vivia uma "metropolização desenfreada". Ainda segundo o autor, a cidade, portanto, estaria marcada uma um heterogeneidade étnica e social, ou seja, um forte aspecto cosmopolita.

Nesse sentido, nota-se a busca por uma identidade, pois para Sevcenko, neste contexto de expansão urbana, a cidade era um enigma para seus próprios habitantes. Segundo o autor, um cronista da época sugeria que ao contrário da Europa, São Paulo seria uma "Babel Invertida", pois enquanto a primeira dividia os homens pelo ódio, a capital paulista os unia, agregava e fundia os mais diversos povos e raças. Ora o mito, entretanto, destoava fortemente da realidade, pois apesar da capital agregar muitos indivíduos, os imigrantes, por exemplo, viviam situações extremamente precárias, assim como os negros, habitando cortiços, moradias insalubres, expostos a epidemias e cumprindo exaustivas jornadas de trabalho. Logo, Sevcenko sugere que ao contrário do que apregoava o mito, para estes sujeitos a projeção da cidade de São Paulo evocaria mais o "Cativeiro da Babilônia"”.

A Faculdade de Medicina de São Paulo nasce, conforme atesta André Mota, entre outras motivações, de certo modo, também desse anseio de identidade. Era importante que o estado, seguindo o exemplo do Rio de Janeiro e da Bahia, tivesse sua própria escola médica. Formando sua "própria gente", objetivava-se chegar a um pensamento médico paulista propriamente dito. ${ }^{8}$ Em meio a muitos esforços e debates no mês de dezembro de 1912 surgia a Faculdade de Medicina de São Paulo, contando com o apoio da Fundação Rockefeller e direção do Dr. Arnaldo Vieira de Carvalho. ${ }^{9}$

É válido também destacar que no campo da Saúde Pública, como demonstra Gilberto Hochman, São Paulo ocupou lugar privilegiado na condução de suas políticas na área da saúde, uma vez que buscou sua independência nas soluções sanitárias, desatrelada dos órgãos federais. ${ }^{10} \mathrm{O}$ estado tornou-se referência no combate a doenças e reformas sanitárias.

Concomitante ao avanço do sanitarismo, o movimento higienista em finais do século XIX era aderido por muitos médicos e ganhava força no Brasil, principalmente com a fundação do Instituto Oswaldo Cruz no Rio de Janeiro em 1901. ${ }^{11}$ Inspirada também pelos cientificismos estrangeiros, a Faculdade de 
Medicina de São Paulo, logo em sua fundação, instituiu a cadeira de Higiene, e mais tarde, em 1918, surgiria o Instituto de Higiene.

Observa-se que desde finais do século XIX, a medicina passava a se interessar não só pela cura individual do enfermo, mas também se preocupava em formas de controle das epidemias, localização de habitações insalubres, as condições do ar e da água, etc. Neste período observa-se a "instauração de uma nova medicina, que incorpora ao seu saber os de ciências emergentes e toma como seu objeto não só o indivíduo enfermo, mas o corpo social, enquanto espaço de promoção de saúde". ${ }^{12}$ Parte deste novo discurso médico tinha como fundamento teórico a corrente higienista, com suas bases assentadas nos estudos de lamarckismo e neolamarckismos, especialmente pela presença da tradição francesa na ciência brasileira. Não à toa, tanto na eugenia como no sanitarismo, a crença de médicos em torno de fundamentos neolamarckianos era uma constante, sobretudo na relação do ambiente com a hereditariedade. ${ }^{13}$ Além disso, acreditava-se que a prevenção moral estava associada à prevenção física. Por este motivo, de acordo com os higienistas, era preciso que se fixassem na sociedade padrões normativos de comportamentos que seriam, supostamente, saudáveis e higiênicos, livrando-a de seus vícios e maus hábitos que comprometiam, conforme veremos a seguir, inclusive o progresso da nação brasileira.

Segundo Jurandir Costa, a medicina conseguiu adentrar no espaço urbano e nele imprimir as marcas de seu poder pelo o apoio do Estado na sustentação de suas políticas de saúde e de higiene. De acordo com o autor, desde o século XIX já era possível notar o apoio do Estado brasileiro à medicina e às práticas higiênicas: "O Estado brasileiro que nasce com a abdicação é o motor-propulsor do súbito prestígio da higiene. A atividade médica coincidia e reforçava a solidez de seu poder, por isso recebeu seu apoio" ${ }^{14}$. Nesse sentido, ao longo do final do século XIX e início do XX, podemos notar como cada vez mais os médicos buscaram legitimar seus discursos à sociedade.

O pesquisador Emerson Elias Merhy destaca que os médicos foram os profissionais que mais se manifestaram e formularam projetos para a Saúde Pública ao longo do século XX. Segundo ele, além do fato do campo definir seu objeto ação, a predominância dos médicos no setor de Saúde Pública se deveu também: "ao fato de os médicos terem se tornado uma categoria legítima para "falar" das políticas de saúde, como consequência de um conjunto de determinações históricas" ${ }^{15}$. Logo, a medicina voltou-se para um controle do cotidiano, pois segundo Margareth Rago: "Os médicos procuraram apresentarse como a autoridade mais competente para prescrever normas racionais de conduta e medidas preventivas, pessoais e coletivas, visando produzir a nova família e o futuro cidadão" 16

Em vista dos estudos de Rodolpho Telarolli Junior, nas primeiras décadas do período republicano brasileiro, a febre amarela, seguida da 
varíola e da febre tifóide, constituíam as grandes epidemias que ameaçavam a população, atingindo altos índices de mortalidade. ${ }^{17}$ No entanto, podemos notar que a sífilis também era uma moléstia muito presente no Brasil. O autor Sérgio Carrara, ao estudar a construção social da sífilis na sociedade brasileira, nos conta da presença dessa enfermidade em todas as regiões do país e, inclusive, "firmemente instalada em São Paulo"18, e apesar de afetar sobretudo a população mais carente, a sífilis atingia os indivíduos de todas as camadas sociais.

A sífilis, segundo Carrara, era encarada como fruto de "um exercício sexual imoderado"19, simbolizava aquilo que os maus hábitos de conduta ocasionavam, dado este fato tal enfermidade será amplamente discutida pelos médicos higienistas, que irão refletir sobre meios de tratamento e cura desta enfermidade, mas também em medidas profiláticas e saneadoras, ou seja, formas de prevenção da doença, que incluíam o desaconselhado de hábitos considerados imorais que, supostamente, muitas vezes ocasionavam essa e outras doenças.

Ainda de acordo com Carrara a sífilis era tida como uma "verdadeira caixa de Pandora". Acreditava-se que tal enfermidade, devido à multiplicidade de lesões que provocava, acarretava uma série de outros problemas à saúde que muitas vezes ocasionavam a morte do enfermo. A sífilis poderia ocasionar outros males como, por exemplo, angina de peito e afecções das artérias, tuberculose, câncer da cavidade bucal, além de poder levar o indivíduo à loucura, por estes e tantos outros motivos a sífilis era um fator de grande preocupação para os médicos. ${ }^{20}$

\section{É melhor prevenir do que remediar. Das medidas profiláticas no combate à sífilis}

A Revista de Medicina tem seu primeiro número publicado no ano de 1916, e possuía por objetivo: "vulgarisar as boas doutrinas e de disseminar, per entre os seus associados, aquelles dos principios que os devem guiar e a que se devem jungir no exercido da sua futura profissão"21. Segundo o catedrático Ovídio Pires de Campos, o empreendimento de criação de uma revista médica não era inédito, no Brasil já circulavam outras do gênero, por exemplo, as revistas Gazeta Médica da Bahia e Brazil Médico no Rio de Janeiro. ${ }^{22}$ Aliás, a trajetória de impressos médicos especializados era uma realidade desde o século XIX, com a criação do Sociedade de Medicina do Rio de Janeiro, em 1829, estaria em circulação o Semanário de Saúde Pública: pela sociedade de medicina do Rio de Janeiro (1831-1835), uma continuidade do Propagador das ciências médicas (1827-1828). ${ }^{23}$

No ano de 1918 o Professor Dr. Celestino Bourroul, catedrático da Faculdade de Medicina e Cirurgia de S. Paulo, publicava na Revista de Medicina um artigo intitulado: "Tratamento da syphilis", no qual afirmava: 
Reveste este terrível mal todas as feições, mascara muitas moléstias, insinua-se pelo seu contagio fácil em todos os meios, estigmatisa gerações e gerações, lesa todos os órgãos, degenera raças, emfim é a grande avaria. "Memento lues" é a phrase que deve sempre soar aos ouvidos do clinico; "delenda lues" é a tarefa momentosa do medico e do hygienista, neste movimento eugenico actual. ${ }^{24}$

Nesta fala podemos notar o aspecto degenerativo, enfatizado pelo autor, supostamente causado pela sífilis. Tal enfermidade era considerada hereditária, logo comprometia não só a saúde do enfermo como de toda a sua prole. ${ }^{25}$ Sendo assim: "Syphilis hereditária seria aquella transmittida da mãe ao feto atravéz da placenta, apparecendo naquelle a moléstia já em sua phase secundaria ou septicemica, sem o apparecimento da lesão primaria" ${ }^{26}$. Além disso, do ponto de vista eugênico a sífilis comprometeria raça, sendo considerada, portanto, um fator de degeneração racial. ${ }^{27}$

Nas publicações que encontramos na Revista de Medicina, vários autores destacam o importante papel da profilaxia no combate à sífilis. Este pensamento era próprio da corrente higienista, conforme já afirmamos tão em voga neste período, que acreditava que a prevenção era tão importante quanto a busca pela cura, conforme afirma Paulo Godoy: "o papel da medicina não é apenas receitar purgantes e pillulas sedativas ou extirpar um órgão doente. Mas impedir a doença, prever o mal"’28. Uma das medidas profiláticas defendidas em relação à sífilis seria a educação sexual, vários médicos defendiam que a população, principalmente os jovens, precisaria ter conhecimento sobre seus corpos e sobre as relações sexuais, pois só assim poderiam compreender a gravidade das doenças venéreas e como elas eram contraídas. Para tanto, ainda em seu artigo Celestino Bourroul afirmava:

Meios não vemos senão um ensaio de prophylaxia pela educação sexual, na família, nas escolas, educação moral animada pela religião. Os educadores, diante do medo de provocar curiosidades malsans, fogem do problema, que deve ser encarado de face e não contornado assim. O resultado é que os jovens, solicitados pelas razões da edade, atiram-se ao vicio, na mais completa ignorância, contrahindo bem cedo muitas moléstias. ${ }^{29}$

Nota-se que esta proposta ainda não era bem aceita em outros meios, principalmente no meio religioso, pois acreditavam que informando os jovens sobre assuntos de ordem sexual, estimulariam a curiosidade, levando-os a praticarem ainda mais cedo tais atos. No entanto, a defesa da educação sexual se dava pelo fato de que, segundo Celestino Bourroul, era melhor que os jovens 
obtivessem tal conhecimento através de seus pais e mestres, do que através de amigos, "que logo se positivam em actos immoraes, tão préjudiciaes, pelo abalo que trazem à saúde, senão por moléstias irremediáveis" 30 .

Mais tarde, no ano de 1924, o tema da educação sexual seria novamente enfatizado na Revista de Medicina pelo artigo de Pedro de Alcantara, intitulado: "Conselhos de hygiene sexual e moral". Já de início o autor afirma que estes conselhos se destinariam aos rapazes, para lhes fornecerem alguns conhecimentos das "coisas sexuais", e também para que estes em uma de suas "aventuras" não fossem surpreendidos com alguma doença que poderia provocar as "mais funestas consequências" ${ }_{31}$. Segundo o autor, em uma determinada idade, sobretudo na juventude, os rapazes veriam "despertar seu instinto sexual" e, no entanto, não haveria ninguém que pudesse instruí-los de maneira correta, pois os pais e professores não tocavam neste assunto: "crendo respeitar assim um pudor que elles acham natural, mas não vendo que com isso se tornam responsáveis pelos desfortunios que o rapaz, inexperiente, procura para si mesmo" 32 . O objetivo de Alcantara se assemelha àquele proposto anteriormente por Celestino Bourroul em 1918. O autor reforça sua intenção de transmitir alguns conhecimentos aos jovens rapazes, como uma fonte segura, na qual eles pudessem confiar:

Terão assim os rapazes informações mais sinceras, mais puras, mais e cientificas do que as que são dadas por companheiros desvirtuados e corruptos que outra coisa não fazem senão envenenar para todo o sempre a vida dos rapazes incautos que thes caem nas garras. ${ }^{33}$

Deste modo, assim como Bourroul, Alcantara defende então a "educação sexual". Os jovens, em sua opinião, precisavam ter conhecimento do seu corpo, sua anatomia e fisiologia. Assim, entenderiam os perigos das doenças venéreas. Além disso, ambos os autores fazem menção à continência sexual, e como haveria nesse período um discurso que supostamente, apontaria os malefícios desta à saúde humana. Afirma Celestino Bourroul:

A continência é condemnada em nome da physiologia, dizem alguns, de modo que a incontinencia é apregoada em nome da mesma physiologia. O resultado é que nós, médicos, vemos a cada passo as conseqüências nefastas destas necessidades sexuaes e nunca vemos os malefícios da continência, assim que já se exprimia o grande Fournier. ${ }^{34}$

Por sua vez, o artigo de Pedro de Alcantara, propõe desmistificar tal ideia, pois podemos perceber que este assim como Bourroul, também acreditava que a continência não traria nenhum dano à saúde humana, ao contrário, ela 
seria benéfica, pois livraria a população das moléstias venéreas: "Propondonos agora a mostrar a compatibilidade da continência sexual com a saúde, procuraremos responder a todas as accusaões (sic) que em tal sentido fazem os adversários da abstinência sexual" ${ }^{35}$.

Sendo assim, apesar destes médicos defenderem a educação sexual, também eram favoráveis à castidade como medida preventiva. Nesse ponto, o discurso higiênico se aproxima do religioso e, apesar de em diversos pontos existirem divergências entre suas concepções e objetivos, observamos que os médicos higienistas ao fazerem a associação entre moral e saúde, acabaram por defender condutas próximas daquelas apregoadas pelo discurso católicocristão, entre elas a da continência sexual antes do casamento. Conforme sintetiza Jurandir Costa: “A higiene retomou a problemática religiosa em outro estilo e com novos fins" "36. A intenção de promover a educação sexual, para os médicos higienistas objetivava, portanto, dar uma noção precisa da ameaça que significava a liberdade sexual.

Nesse sentido, de acordo com Costa, tal educação acabava por desencadear uma verdadeira repressão sexual. ${ }^{37}$ Para embasar sua defesa da continência sexual Pedro Alcantra afirmava: "No corpo e no espírito desses rapazes [castos] não há uma moléstia ou uma mancha qualquer; pelo contrário, são uma garantia de que irão constituir uma família sã, com filhos sadios e fortes, que bem dirão os que lhe deram essa saúde" ${ }^{38}$.

Ainda segundo Alcantara, era necessário, portanto, que se fizesse compreender entre os jovens a importância de constituir uma família, valorizando-se a formação de uma prole saudável. Assim, mais uma vez, notase a preocupação de diversos intelectuais com a saúde e a hereditariedade da população ligando-as a um ideal de progresso nacional.

No entanto, logo se constatava que existia "um quadro sanitárioeducacional extremamente precário" ${ }^{39}$, deste modo, do prisma higiênico era preciso trabalhar na construção de um país forte e sadio. Acreditava-se que o Brasil precisava passar uma imagem de credibilidade ao mundo, ou seja, conquistar o progresso e o status de civilização baseando-se nos padrões europeus se tornara uma obsessão para a nova burguesia. ${ }^{40}$ Como expõe Valéria Guimarães, este conjunto de ideias propagadas por parte da elite intelectual (médicos, juristas, jornalistas, etc.) fez parte de um "projeto regenerador" que buscava legitimar o controle social, além de idealizar a formação de um novo cidadão brasileiro. ${ }^{41}$ Para a autora:

[...] os eruditos se esmeravam em delinear as teorias que a um só tempo dessem conta de traçar éticas de comportamento ligadas aos ideais de progresso e civilidade e de caracterizar o que era considerado, por assim dizer anormal e patológico, prejudicando o caminho evolutivo positivo. ${ }^{42}$ 
A sífilis pensada então como uma enfermidade própria do desregramento sexual e da imoralidade, "intensificou o terror que envolvia as atividades sexuais" ${ }^{43}$, além de ser considerada como um fator degenerativo que atravancava o progresso nacional e estigmatizava as gerações. Talvez por ser considerada como doença própria daqueles que teriam um "comportamento desregrado" a sífilis era comparada com o alcoolismo, conforme podemos notar nesta fala de Paulo de Godoy:

Quando um homem se alcooliza, fuma ópio, se embebeda com ether, se intoxica pela cocaína, quando se expõe voluntariamente á syphilis, não commette apenas um attentado contra a sua própria pessoa, contra a sua vida; mas prepara um a hereditariedade lamentável de degneerados (sic), de desequilibrados, de tarados, de criminosos. ${ }^{44}$

Eleito como um mal social por higienistas sociais, o álcool desde o século XIX representaria um componente degenerador do corpo e responsável por males físicos e sociais. Esta visão era compartilhada por médicos também na Argentina, como mostrou Diego Armus, onde o alcoolismo era um signo da degeneração sendo inclusive associado com a tuberculose e a criminalidade..$^{45}$

No entanto, ao contrário de muitos males, doenças ou vícios considerados particulares de determinados povos ou raças "inferiores", a sífilis era considerada uma enfermidade universal, podendo atingir toda a população, sem distinção de grupos étnicos ou socioeconômicos. ${ }^{46}$ Além da crença de contaminação por meio de relações sexuais com indivíduos infectados, intelectuais como Alcantara, por exemplo, acreditavam em outras modalidades de contágio, pois, segundo o mesmo, a sífilis "Pode ser apanhada por uma multidão de maneiras, por um simples beijo, pelo emprego de objectos infeccionados (louça, talher, navalha, lápis, instrumentos de musica, etc.) ou pelo uso de roupas contaminadas" ${ }^{\prime 47}$. Em tempo, a posição de Alcantara evidencia o contagionismo ${ }^{48}$ como uma via de transmissão para a sífilis.

$\mathrm{Na}$ análise das fontes notamos a preocupação dos médicos higienistas com a instituição familiar e matrimonial. Tal fato pode ser exemplificado pelas alegações de que muitas mulheres ao se casarem com um noivo contaminado por uma doença venérea, como a sífilis ou a gonorreia, supostamente adquiridas devido a um comportamento impróprio deste na juventude ou mesmo pela prática do adultério, acabava muitas vezes por contaminar a esposa e consequentemente toda sua prole:

$\mathrm{Na}$ enfermaria de Ginecolojia e no Ambulatório [da Faculdade de Medicina de São Paulo] da mesma clínica, onde trabalhamos, vemos diariamente moças contaminadas e infeccionadas pelo marido. É fatal: o indivíduo se caza 
doente; contamina a espoza; abortos; prole defeituoza e degenerada. Na enfermaria de crianças vemos a grande porcentagem dos heredo-sifilíticos. Assim, permitir ao enfermo o direito de perpetuar o seu mal, é dolorozo, é lastimável. ${ }^{49}$

A sífilis era responsabilizada pela maioria dos abortos, boa parte dos casos de mortalidade e por $80 \%$ dos casos de debilidade congênita. ${ }^{50}$ Os filhos de sifilíticos, segundo o discurso médico, seriam crianças fracas e disformes. $\mathrm{Na}$ ótica de Arnaldo Bacellar, por exemplo, a surdo mudez congênita, ou seja, aquela adquirida desde o nascimento, poderia ser uma consequência do estágio luético dos pais: "Hereditariedade syphilitica, consiste na transmissão de um meio propicio ao apparecimento de distrophias e degenerescencia, entre as quaes está a surdo mudez"s1

Diante deste fato, Paulo de Godoy e muitos outros médicos deste período, se posicionaram a favor da proposta do chamado "exame médico pré-nupcial", que funcionaria, na visão destes profissionais, como uma medida profilática em relação a estas doenças transmissíveis. Tal proposta defendia que todos aqueles que almejassem contrair o matrimônio (homens e mulheres) deveriam passar por tal exame no qual um médico iria averiguar se estes possuiriam "sanidade física e mental", ou seja, se eram saudáveis e livres de quaisquer fatores considerados degenerativos.

Se o exame indicasse o resultado positivo teriam o aval para casar. Caso contrário, quando um dos nubentes possuísse alguma moléstia como a sífilis ou tuberculose, teriam seu matrimônio adiado quando houvesse perspectiva de cura, caso contrário, o casamento seria vetado pelos médicos. Sobre o exame médico pré-nupcial, diz o médico Antônio de Almeida Junior: "O exame medico antes do casamento constitue providencia de alta utilidade social e, de dia para dia, mais necessária" ${ }^{2}$. Segundo ele, ao contrário do que ocorria nos tempos mais primitivos, o homem civilizado não poderia mais confiar em seus instintos para escolher seu companheiro (cônjuge). Sendo assim: "Com esse exame medico pre-nupcial, ter-se-ia corrigido, ou attenuado, de maneira simples e pratica, a insufficiencia da selecção natural, diffcultando-se o contagio conjugal e a transmissão hereditaria de moléstias e taras" ${ }^{53}$. Francisca Praguer Fróes foi uma das primeiras mulheres a se formar em medicina no Brasil, a baiana era uma defensora do exame médico pré-nupcial e também do que ela chamou de "casamento monogâmico verdadeiro". Em sua visão, a poligamia informal dos homens contaminava as mulheres com doenças venéreas que quando não as deixava estéreis as levava à morte. ${ }^{54}$ Por este motivo, os médicos reafirmavam a importância do exame pré-nupcial. Nas palavras de Paulo de Godoy:

Nas sociedades sem o exame pré-nupcial a syphilis atravessa o seu ciclo medonho: da prostituição e da ralé passa para a 
alcova nupcial, determinando proles mirradas e tropegas e agindo, consequentemente na formação de um povo fraco e enfermiço. Daqui se levanta imperativamente a necessidade da instituição do exame pre-nupcial obrigatório, como elemento de grande importância para a defesa da raça e da sociedade..$^{55}$

Por meio dessas fontes, entende-se a ambição de parte da ala médica na constituição da obrigatoriedade do exame pré-nupcial em todo o país. Em defesa da medida, podemos citar o posicionamento de intelectuais como Agostinho de Souza Lima, Afrânio Peixoto, Renato Kehl, Rodrigues Doria, Almeida Júnior e Luiz Palmier. Assim, o exame médico pré-nupcial obrigatório seria uma medida indispensável e necessária para livrarem-se de vários dos supostos males da sociedade. Contudo, tal exame não era uma singularidade brasileira. $\mathrm{O}$ assunto era debatido entre eugenistas e intelectuais em vários países tanto da Europa como da América, sendo inclusive implantada em alguns países conforme afirma Paulo de Godoy:

Em todos os paizes ciozos da raça e da nacionalidade, ha obrigatoriedade do exame pré-nupcial. Nas repúblicas do Prata o encontramos na Argentina, Uruguái e, mesmo, no pequenino México. Só a República do Brazil, moça peralta e sentimental, não cuida desse grande elemento para Eugenia da raça. Lamentavel. Dolorozamente lamentavel. ${ }^{56}$

Mostrando conhecimento de causa, Godoy citaria a Turquia, onde o então novo presidente instituíra o exame pré-nupcial, obrigatório e indispensável para a realização do matrimônio. O médico brasileiro considerava a lei do exame pré-nupcial uma lei sábia e patriótica. Por esse motivo lamentava sua inexistência no Brasil - e, aqui, fica claro como o país tentava se inserir nesta discussão que ocorria no campo da medicina estrangeira. O médico Almeida Júnior também nos fala de outros países adeptos da lei: “A Suecia, a Noruega e a Dinamarca não ficaram no terreno das doutrinas: instituíram por lei (...) o attestado medico obrigatório" 57 , segundo ele, também nos Estados Unidos vinte e três estados estabeleceram o exame pré-nupcial por lei.

Muitos médicos acreditavam que o Código Civil de 1916 deveria ser reformulado, pois apesar de listar alguns fatores de impedimentos matrimonias, poderia se fazer mais em prol da formação eugênica no país. Afrânio Peixoto transcreve do Código Civil, art. 219: "Considera-se erro essencial sobre a pessoa do outro conjuge: III. A ignorancia, anterior ao casamento, de defeito fisico irremediavel ou de moléstia grave e transmissivel por contagio ou herança, capaz de pôr em risco a saude do outro cônjuge ou se sua descendencia" ${ }_{58}$. 
De acordo com Afrânio Peixoto, a possibilidade trazida pelo Código Civil de anulação do casamento quando posteriormente um cônjuge tomasse conhecimento de uma doença grave e transmissível do outro representava, em sua opinião, apenas uma providência. Em suas palavras, significaria remediar depois de "já consumado o mal". Para os higienistas - e eugenistas - convinha mais evitar ou prevenir que estas moléstias fossem transmitidas e isto seria possível através do exame pré-nupcial, uma vez que por meio desse, os indivíduos doentes, entre eles os sifilíticos, seriam impedidos de contrair o matrimônio. Para Peixoto:

Depois do mal feito "somaticamente" será muito pouco provavel que o cônjuge fraudado, contaminado, impregnado ou prenhe (se foi a mulher), reclame contra a deslealdade que presuma esse $n^{\circ}$ III do Art, 219, do Codigo Civil. Não conheço caso nenhum de anulação por esse motivo. E não serão poucos os casos em que poderá ser invocado. As leis estúpidas são ineficazes e apenas compõem as legislações. ${ }^{59}$

Vale salientar que, ainda em 1897, Agostinho de Souza Lima em uma de suas conferências pediu apoio para a Academia Nacional de Medicina para transformar o exame médico pré-nupcial obrigatório em lei. Sendo assim, é considerado um dos precursores nos esforços de tornar o casamento numa instituição higiênica. Isso sugere a presença da discussão dos exames muito antes do aparecimento e institucionalização da eugenia no Brasil. Conforme afirma Renato Kehl:

Pela ordem chronologica, entretanto, creio não errar, dizendo caber ao Prof. Souza Lima os primeiros esforços em prol da defesa eugênica da nacionalidade. Em 1897 pediu à Academia Nacional de Medicina o apoio para o estabelecimento de uma lei tornando obrigatório o exame pré-nupcial e estatuindo o impedimento legal aos candidatos tuberculosos e syphilicos. ${ }^{60}$

Nos termos legislativos, o médico Amaury de Medeiros apresentou em 1927 um projeto de lei sobre o exame médico pré-nupcial facultativo à Comissão de Justiça e Saúde do Congresso Nacional. Apesar de seus esforços para alcançar a aprovação de sua ideia, o médico foi acometido pela morte e nunca pôde realizar sua ambição. Mais tarde, em 1936, surge outro projeto de lei sobre o exame médico pré-nupcial proposto pelo deputado Nicolau Vergueiro e apresentado a Câmara Federal. Em seu projeto é citado o trabalho de Amaury de Medeiros como referência:

Para o nosso trabalho, servimo-nos, em parte, e com a boa parte, do projeto do deputado Amaury de Medeiros, em 
1927, e que teve pareceres favoráveis nas Comissões de Saúde e Justiça da Câmara de então, e, assim procedendo, prestamos homenagem à memória d'aquele colega, tão cedo e desastradamente roubado à vida, e que foi o pioneiro da idéia, nesta Casa. ${ }^{61}$

O projeto de lei exigia o atestado médico que comprovasse a sanidade física e ausência de doenças contagiosas que comprometessem uma prole saudável. O casamento realizado sem o exame seria considerado nulo. Contudo, segundo a autora Cynthia Pereira Vilhena, a lei não chegou a ser regulamentada pelo Executivo. ${ }^{62}$

Conforme podemos observar e corroborar com José Leopoldo Antunes, apesar de todos os esforços e a da insistência médica sobre a importância do exame pré-nupcial obrigatório, como uma forma de impedir o casamento e a consequente procriação dos doentes e degenerados, a obrigatoriedade do exame nunca chegou a ser implantada como lei em âmbito nacional da forma como os médicos esperavam. Para Antunes, isso demonstra os limites da intervenção médica no período. ${ }^{63}$ Este caso exemplificava a reflexão de Madel Luz ao afirmar que se tais propostas tivessem sido concretizadas do modo como os médicos almejavam, estes teriam conquistado um grande poder de intervenção social "mas historicamente vemos que isto não ocorreu" ${ }^{64}$.

\section{Depois que o "mal" estivesse feito. Das formas de tratar}

Em 1922 o Dr. Aguiar Pupo publicou um artigo na Revista de Medicina abordando o problema da sífilis, intitulado: "Uma campanha salutar: a luta contra a syphilis em São Paulo - Sobre a organização de dispensários antivenereos e sua função prophylactica". O autor fazia referência à profilaxia da sífilis como um problema higiênico. Em sua opinião, a profilaxia seria a principal forma de combate a esta moléstia. Apesar disso, também era preciso realizar o tratamento necessário naqueles indivíduos contaminados. A Academia Nacional de Medicina aconselhava a criação de postos médicos para o tratamento gratuito para a população carente. Segundo Aguiar Pupo, em 1918, o Serviço Sanitário do Estado de São Paulo na administração Arthur Neiva, criou cinco postos de profilaxia e tratamento gratuito da sífilis. No período do mês de setembro de 1918 a dezembro de 1919 foram matriculados no total 1.467 doentes, destes sendo: 1.022 homens; 455 mulheres; 472 brasileiros e 995 estrangeiros. ${ }^{65}$ Ainda segundo o autor, estes postos foram fechados em 20 de agosto de 1920, por deliberação do Dr. Arruda Sampaio, que era o então diretor do Serviço Sanitário, sob o intuito de reabri-los mais tarde, com uma organização mais eficiente. No entanto: "Em São Paulo, o Centro Acadêmico "Oswaldo Cruz" não se conformando com o acto do director do Serviço Sanitário, em 29 de Agosto de 1920 reabriu os postos fundados sob a 
sua ardorosa iniciativa, sendo-nos então confiada a sua direcção scientifica" Sendo assim, neste artigo Pupo afirma que o Primeiro Posto de Tratamento Gratuito da Sífilis foi criado em 29 de Agosto de 1920 e mantido pelo Centro Acadêmico Oswaldo Cruz. Para o atendimento nestes postos de saúde o paciente deveria declarar sua baixa renda através do "attestado de pobreza dado pela policia ou requisição dos médicos de hospitaes de caridade, na maioria da Santa Casa de Misericórdia" ${ }^{7}$.

Sob o título de "Liga de combate à Syphilis", atuavam nestes postos gratuitos de saúde, sobretudo os estudantes de Medicina da Faculdade:

Liga de Combate á Syphilis foi reorganizada em 1920 pelos acadêmicos do Centro Oswaldo Cruz, que a vêm mantendo graças a esforços próprios e com auxílios do Serviço Sanitário, da Santa Casa de Misericórdia, do Dispensario Clemente Ferreira e da sociedade paulistana. A Santa Casa e o Dispensario Clemente Ferreira cederam á Liga as dependências onde foram installados os seus postos de prophylaxia, até hoje em funccionamento. ${ }^{68}$

Conforme demonstra um artigo do ano de 1928, de autoria desconhecida, parte da renda adquirida para em favorecimento do funcionamento dos postos provinha de festivais beneficentes onde participavam a sociedade paulista ou "as melhores famílias paulistanas"

Para detectar a presença da sífilis era realizado um exame sanguíneo chamado "teste de Wassermann" 70 . Assim diagnosticada havia três modalidades clínicas da sífilis: "Syphilis primaria, Syphilis secundaria, syphilis terciaria e syphilis latente" ${ }^{\prime}$. A cada um destes níveis da doença era aplicado um tipo de tratamento específico. No estágio inicial da sífilis ocorreria o aparecimento de um cancro inicial, seu o tratamento era feito "pelo arsenobenzol ou pelo mercúrio" ou ainda injeções de óleo cinzento. ${ }^{72}$ No estágio secundário, de acordo com Aguiar Pupo, surgiriam lesões superficiais por todo corpo do enfermo. "Nos nossos serviços os casos de syphilis secundaria são tratados pelo 914 (Novarsenobenzol) [...] emprego do 606 (arsenobenzol) [...] Successivamente á cicatrisação das lesões contagiantes e outras manifestações da syphilis secundaria os doentes são submettidos ao tratamento mercurial preventivo" 73 . $\mathrm{Na}$ sífilis terciaria as lesões seriam mais profundas e ulcerosas: "os doentes de syphilis terciaria são tratados nos nossos postos pelas injecções de iodeto de sódio seguidas de tratamento de fundo pelo mercúrio, um a vez obtida a cicatrisação das lesões" "74.No estágio quaternário ou latente, existiram reservas em relação ao uso do 914 (Novarsenobenzol), o mais adequado seria o uso do mercúrio. Pois este primeiro: “[...] é um remédio cujas indicações devem ser mais restrictas que as do mercúrio, pelos accidentes graves a que expõe o doente e a responsabilidade do medico" 75 
O mercúrio conforme observamos era muito utilizado no tratamento da sífilis, em todos os estágios da doença ele era recomendado. Tal medicamento seria capaz de agir contra o agente infecioso da lues (treponema pallidum) e de destruir a maior parte das toxinas existentes no organismo sifilítico. ${ }^{76}$ Aguiar Pupo aponta as vantagens do mercúrio no tratamento da sífilis, por este: "ter acção muito mais duradoura e constituir o verdadeiro medicamento da syphilis, impedindo a propagação da moléstia para os descendentes, desde que o tratamento seja intermittente e prolongado segundo a pratica estabelecida por Fournier"'77. Contudo, Celestino Bourroul atenta para o fato de que seu uso deve ser controlado devido aos males que poderia causar aos rins do paciente: "E a demais, nestes tratamentos intensivos, tenha-se muito em conta o estado renal, porque o mercúrio é um grande veneno para os rins; e raro não é que os syphiliticos apresentem nephrites, ligadas a outras etiolagias, quando a causa está no mercúrio abusado"78. De acordo com Carrara, o mercúrio seria utilizado, sobretudo até meados da década de 1940, quando se generaliza o uso de penicilina. ${ }^{79}$

Neste período podemos notar que existia um otimismo de alguns médicos não só em relação à cura da sífilis, mas também quanto ao seu total desaparecimento. Esse tom esperançoso se dava, sobretudo, pela concepção da potencialidade do tratamento com o uso dos sais de arsênico. Em 1927 o professor Rubião Meira escrevia em seu artigo à Revista de Medicina que a sífilis estaria quase a desaparecer. A doença já não causava tantas mortes como antes: "os seus effeitos perniciosos vão desaparecendo [...] Não tem comparação, o que se vê hoje e o que se encontrava annos atraz, antes da therapeutica arsenical" ${ }^{\circ}$. Carrara, demostra que anteriormente, em 1913, Afrânio Peixoto afirmava que através da aplicação do tratamento correto, livre de charlatanismo, a sífilis logo iria desaparecer. Porém, ainda segundo o autor, ao longo dos anos notou-se que "o tratamento com os arsenobenzóis nem sempre curava, embora fizesse com que as lesões contagiantes cicatrizassem rapidamente" ${ }^{81}$.

Apesar de muitos médicos, principalmente sifilógrafos, considerarem a sífilis como uma doença que acarretava uma série de outras moléstias, ou seja, ser a "chave de toda a patologia" alertar para que se tivesse cuidado ao assumir que uma patologia qualquer seria ocasionada pela sífilis. Conforme dizia Ovidio Campos: "atira-se á conta da syphilis muito mal que ella, nem directa e nem indirectametne, acarreta" Nesse sentido, o mesmo chamava atenção para o fato de que para o clínico chegar a tais conclusões deveria recorrer aos dados teóricos e confrontá-los com a experiência prática. Caso contrário, ficar-se-ia apenas no campo das hipóteses. Segundo Carrara, somente no contexto do pós-Segunda Guerra é que a sífilis deixa de receber a enorme atenção adquirida até então: "a moléstia perde parte dos enormes poderes conferidos pela crença em sua onipresença 
no organismo humano" ${ }_{84}$. A descoberta da penicilina, das novas tecnologias e testes laboratoriais contribuíram para a essa redefinição da sífilis.

\section{Considerações finais}

Conforme procuramos demonstrar, a cidade de São Paulo no início do século XX vivenciava seu "momento de arranque da urbanização" que coincide também com o momento que se ampliava a atuação da medicina na capital paulista ${ }^{85}$ A chegada de imigrantes, o fim da escravidão e a formação da incipiente classe operária, significaram um expressivo aumento demográfico, que revelou uma série de problemas de ordem sanitária. A formação de cortiços, moradias insalubres e a forte incidência de várias epidemias, indicavam um panorama urbano caótico, logo "diante desse cenário alterado redefinia-se a atuação médica no país" ". O dito "problema sanitário" como mostra também dizia respeito a uma questão de identidade nacional, mobilizando a elite política na busca de soluções para a configuração da identidade do "povo". 87

Além das preocupações de ordem sanitária, a medicina volta-se para um controle do cotidiano, buscando implantar normatizações de comportamento, alimentação, vestuário e sexualidade. O movimento higienista progride em relação direta com o desenvolvimento urbano. ${ }^{88}$ Sob o lema da higiene os médicos buscaram intervir ativamente na sociedade, de modo que almejavam construir um novo cidadão brasileiro: civilizado e sadio.

A sífilis seria vista como consequência de um comportamento impróprio e imoral, marcado por excessos e vícios. Isto é, além da cartilha moral que se estabelecia diante aos comportamentos, havia também em pauta a higiene mental, onde a sífilis além de constituir um agente de degeneração era objeto da psiquiatria e tomando atenção de intelectuais como Juliano Moreira, um dos pioneiros da psiquiatria nacional ${ }^{89}$ As concepções da sífilis nos espaços da higiene é consequência da sua leitura enquanto um mal social, muito em voga na virada na segunda metade do século XIX e primeira do XX.

Nesse sentido, representava justamente aquele tipo de conduta condenável do ponto de vista higiênico. Utilizando de medidas que consideravam profiláticas em relação à sífilis, o discurso higienista defendia a castidade pré-matrimonial e incentivava a educação sexual justamente como um recurso para conscientizar os jovens sobre importância da primeira medida citada. Sem esquecer também da sua potencialidade enquanto dispositivo de controle do corpo e normatização de condutas morais.

Além dos riscos que causava à saúde do próprio enfermo, devido a uma série de outras doenças que supostamente acarretava, a sífilis era tida também como uma enfermidade hereditária. Sendo assim, comprometia não só a esposa(o) como toda a sua prole. Por este motivo tal moléstia se tornava ainda mais perigosa e preocupante aos olhos dos médicos, principalmente 
eugenistas, que buscavam o aprimoramento racial através de nascimentos favoráveis e obtenção de gerações sadias.

Nota-se, portanto, que o movimento médico higienista - e também o eugênico - criou um discurso particular em torno da sífilis, sendo considerada até o pós Segunda Guerra um dos maiores flagelos que acometiam a humanidade. ${ }^{90}$ Além disso, através de sua prerrogativa de que não bastava curar, mas também prevenir, os médicos almejaram estabelecer uma série de imposições à sociedade.

Lutando contra uma suposta degeneração, médicos como Godoy, Alcantara e Bourroul projetavam meios para uma grande intervenção social. Godoy, por exemplo, buscou estabelecer regras e padrões de comportamento, mas também ambicionava um efetivo controle matrimonial e reprodutivo, principalmente por meio da proposta do exame pré-nupcial. Os artigos vinculados a Revista de Medicina nas primeiras décadas do século XX recomendariam e proporiam diversas medidas no combate à sífilis tanto adaptados com um discurso de preocupação nacional calcado nos fatores considerados negativos no que tange à reprodução e à descendência. As publicações no periódico tornam-se documentos interessantes para se perceber o estágio da ciência no hastear de bandeiras contra doenças sociais. A presença das propostas de exames pré-matrimoniais contribuem para percebermos as controvérsias em torno desta doença, mas também como os agentes e atores históricos, na saúde e na política agiam para controlar sua disseminação.

\section{Notas}

1 BOURROUL, Celestino. Tratamento da syphilis. Revista de Medicina, São Paulo, v. 002, n. 008, 1918, p.12. Disponível em < http://www.obrasraras.usp.br/xmlui/bitstream/handle/123456789/4147/Revista_de_Medicina_vol_2_num_8_1918.pdf? sequence=1>

2 Todas as citações encontradas na Revista de Medicina presentes neste artigo foram acessadas e arquivadas em 23 de maio de 2015.

3 NASCIMENTO, Dilene Raimundo do; CARVALHO, Diana Maul de.; MARQUES, Rita de Cássia (Orgs.). Uma História Brasileira das Doenças. Editora MAUAD, Rio de Janeiro, 2006, p. 9; ROSEMBERG, 2002; ROSEMBERG, Charles E. "The Tyranny of Diagnosis: Specific Entities and Individual Experience." The Milbank Quarterly, v. 80, n. 2, 2002, pp. 237-260.

4 MONTEIRO, Y. N., CARNEIRO, M. L. T.(Orgs.). As doenças e os medos sociais. São Paulo, Editora Fap-Unifesp, 2012, p. 10.

5 FLECK, Ludwik. Gênese e desenvolvimento de um fato cientifico. Belo Horizonte: Fabrefactur, 2010.

6 SEVCENKO, Nicolau. Orfeu Extático na Metrópole, São Paulo sociedade e cultura nos frementes anos 20. São Paulo, Cia das Letras, 1992, p. 36. 
7 Idem., p. 39.

8 MOTA, André. O caso da Faculdade de Medicina em 1911. REVISTA USP, São Paulo, n.61, p. 210-221, março/maio 2004. p. 210-21. Disponível em <www.usp.br/revistausp/61/19-andremota.pdf $>$ acessado em 26 de maio 2015, p. 213.

9 Idem; CORREIA. Luciana Cristina. Instituto de Higiene (1918-1929) no estado de São Paulo - a atuação de Geraldo Horácio de Paula Souza e Mário da Costa Galvão. Cad. hist. ciênc., São Paulo, v. 7, n. 1, jun. 2011. Sobretudo pelo advento da República possibilitou-se: "a criação de máquinas administrativas estaduais e a formulação de uma incipiente política de saúde" (TELAROLLI JUNIOR, Rodolpho. Poder e Saúde. As epidemias e a formação dos serviços de saúde em São Paulo. São Paulo, Editora da Universidade Estadual Paulista, 1996, p. 9). Logo, apesar de destacarmos aqui a fundação da Faculdade de Medicina como um importante marco da expansão do campo médico em São Paulo, devemos deixar claro que anteriormente existiram outras instituições que foram fundamentais neste processo, como o Serviço Sanitário de São Paulo (1891), a Sociedade de Medicina e Cirurgia (1895), entre outras. (TEIXEIRA, Luiz Antonio. Ciência e saúde na terra dos Bandeirantes a trajetória do Instituto Pasteur de São Paulo no período 1903 - 1916. Rio de Janeiro: Editora FIOCRUZ, 1995).

10 HOCHMAN, Gilberto. A era do saneamento: As bases da política de Saúde Pública no Brasil. São Paulo: Editora Hucitec Anpocs, 1998, p. 197.

11 LUZ, Madel. Medicina e ordem política brasileira. Rio de Janeiro: Graal, 1982.

12 Idem, p. 105

13 STEPAN, Nancy, Lays. Eugenia no Brasil (1917-1940). In: HOCHMAN, Gilberto; ARMUS, Diego (Orgs.). Cuidar, controlar,curar: ensaios históricos sobre saúde e doença na América Latina e Caribe. Rio de Janeiro: Editora Fiocruz, 2004, p. 346-347.

14 COSTA, Jurandir Freire. Ordem médica e norma familiar. Rio de Janeiro: Graal, 1989, p. 32.

15 MERHY, Emerson Elias. São Paulo de 1920 a 1940 - A Saúde Pública como Política. Os movimentos sanitários, os modelos tecnoassistenciais e a formação das políticas governamentais. Porto Alegre, Editora Rede UNIDA, 2014. Disponível em <http://www.redeunida. org.br/editora/biblioteca-digital/colecao-classicos-da-saude-coletiva/a-saude-publica-como-politica-pdf/at_download/file> acessado em 25 de maio 2015, p. 71.

16 RAGO, Margareth. Do cabaré ao lar: a utopia da cidade disciplinar (Brasil 1890 1930). Rio de Janeiro: Paz e terra, 1997, p. 118.

17 TELAROLLI JUNIOR, op.cit., p. 49.

18 CARRARA, S. Tributo a Vênus: a luta contra a sífilis no Brasil, da passagem do século aos anos 40. Rio de Janeiro: Editora FIOCRUZ, 1996, p. 19.

19 Idem., p. 32

20 Idem., p. 39-40

21 CAMPOS, Ovidio Pires de. Revista de Medicina. Revista de Medicina, São Paulo, v. 001, n. 001, 1916, p. 3. Disponível em: < http://www.obrasraras.usp.br/xmlui/bitstream/handle/123456789/4193/Revista_de_medicina_V_1_n_1_1916.pdf?sequence=1>

22 Conforme destaca Teixeira, a Revista de Medicina não era a pioneira no gênero no estado de São Paulo. Anteriormente existira a Revista Médica, em sua curta duração possuiu sua 
primeira publicação datando o ano de 1889 , sendo que seu último número foi publicado em 15 de fevereiro de 1890 (TEIXEIRA, Luiz Antonio. Ciência e saúde na terra dos Bandeirantes a trajetória do Instituto Pasteur de São Paulo no periodo 1903 - 1916. Rio de Janeiro: Editora FIOCRUZ, 1995, p. 35.)

23 PINHEIRO, Rachel. O que nossos cientistas escreviam: algumas das publicações em ciências no Brasil do século XIX. Tese de Doutorado. Campinas: Instituto de Geociências (UNICAMP), 2009, p. 68-69.

24 BOURROUL, op. cit., p.12.

25 ALCANTARA, Pedro de. Conselhos de Hygiene sexual e moral. Revista de Medicina, São Paulo, v. 005, n. 031, 1924, p. 26. Disponível em: < http://www.obrasraras.usp.br/xmlui/bitstream/handle/123456789/4176/Revista_de_Medicina_vol_5_n_31_1924.pdf?sequence=1>

26 BACELLAR, Arnaldo. Etiologia da surdo mudez. Revista de Medicina, São Paulo, v. 008, n. 039, 1926, p. 6. Disponível em: < http://www.obrasraras.usp.br/xmlui/bitstream/ handle/123456789/4223/S-Revista_de_medicina_8_39_1926.pdf?sequence=1>

27 A eugenia, ciência de Galton, defendia o aprimoramento racial pela obtenção de nascimentos favoráveis, ou seja, formação de proles consideradas sadias, deste modo a nação poderia evoluir. Institucionalizada no Brasil desde o final da década de 1910 no Brasil, a eugenia ganhou muitos adeptos no país e foi interpretada segundo as necessidades nacionais (STEPAN, Nancy Lays. A hora da eugenia: raça, gênero e nação na América Latina. Rio de Janeiro Editora Fiocruz, 2005).

28 GODOY, Paulo de. O exame medico pre-nupcial. Revista de Medicina, São Paulo, v. 012, n. 049, 1927, p. 522. Disponível em: < http://www.obrasraras.usp.br/xmlui/bitstream/ handle/123456789/4231/S_Revista_de_medicina_12_49_1927.pdf? sequence=1>

29 BOURROUL, op.cit., p. 12.

30 Idem., p. 13.

31 ALCANTARA, op.cit., p. 20.

32 Idem.

33 Idem.

34 BOURROUL, op.cit., p. 130.

35 ALCANTARA, op.cit., p. 22.

36 COSTA, op.cit., p. 232.

37 Idem., p. 15.

38 ALCANTARA, op.cit., p. 22.

39 MAI, Lilian Denise. Difusão dos ideários higienistas e eugenistas no Brasil. In: BOARINI, Maria Lucia (org.) Higiene e Raça como projetos: Higienismo e Eugenismo no Brasil. Maringá: Eduem, 2003, p. 45.

40 SEVCENKO, Nicolau. Literatura como missão: tensões sociais e criação cultural na Primeira República. São Paulo: Brasiliense, 1999, p. 29.

41 GUIMARÃES, Valéria. Notícias diversas: suicídios por amor, leituras contagiosas e cultura popular em São Paulo dos anos dez. Campinas: Mercado de Letras, 2013, p. 83. 
42 Idem.

43 DANTAS, Bruna Suruagy do Amaral. Sexualidade, cristianismo e poder. Estudos e Pesquisas em Psicologia, v. 10, n. 3, p. 700-728, 2010, p. 718.. Disponível em <http://www. revispsi.uerj.br/v10n3/artigos/pdf/v10n3a05.pdf>

44 GODOY, op.cit., p. 518.

45 ARMUS, Diego. La ciudad impura. Buenos Aires: Edhasa, 2007, p. 181.

46 CARRARA, op.cit.

47 ALCANTARA, op.cit., p. 25.

48 Cf.: COSTA, M. C. L. Teorias médicas e gestão urbana: a seca de 1877-79 em Fortaleza. História, Ciências, Saúde Manguinhos, vol. 11(1): 2004, pp. 57-74 ; CZERESNIA, D.: 'Do contágio à transmissão: urna mudança na estrutura perceptiva de apreensão da epidemia' História, Ciências, Saúde Manguinhos, vol. 4 (1), 1997, pp. 75-94.

49 GODOY, Paulo de. Pontos de Vista. Revista de Medicina, São Paulo, v. 008, n. 040, 1926, p. 3. Disponível em: <http://www.obrasraras.usp.br/xmlui/bitstream/handle/123456789/4224/S-Revista_de_medicina_8_40_1926.pdf?sequence=1 http://www.obrasraras.usp.br/xmlui/ bitstream/handle/12345 $\overline{5} \overline{7} 89 / 4224 /$ S-Revista_de_medicina_8_40_1926.pdf?sequence=1>

50 CARRARA, op.cit., p. 43.

51 BACELLAR, op.cit., p. 7. Segundo Carrara, somente por volta da década de 1940 que a ideia da hereditariedade sifilítica iria cair em descrédito. Apesar disso, ainda de acordo com o autor, até a Segunda Guerra Mundial, a sífilis ainda será pensada como um dos maiores flagelos que atingiram a humanidade e atuam em seu processo degenerativo. (CARRARA, op.cit., p. 68)

52 ALMEIDA JÚNIOR, Antônio. O exame médico pré-nupcial. São Paulo: Instituto Dona Anna Rosa, 1927, p. 43.

53 Idem.

54 RAGO, Elisabeth Juliska. Outras falas: feminismo e medicina na Bahia (1836 - 1931). São Paulo: Annablume, FAPESP, 2007, p. 1627.

55 GODOY, op.cit., p. 523.

56 Idem., p. 2

57 ALMEIDA JÚNIOR, op.cit., p. 48.

58 PEIXOTO, Afrânio. Novos rumos da medicina legal. Rio de Janeiro: Guanabara, 1938, p. 26.

59 Idem., p. 36.

60 KEHL, Renato. A Eugenia no Brasil. In: Actas e trabalhos Primeiro Congresso Brasileiro de Eugenia. Rio de Janeiro: s. n., v.1, 1929 , p. 52.

61 O EXAME pré nupcial. Correio Paulistano, São Paulo, ano LXXXIII, n.24.672, 21 de agosto de 1936, p. 6.

62 VILHENA, Cyntia Pereira de Souza. Práticas eugênicas, medicina social e família no Brasil republicano. Revista da Faculdade de Educação, São Paulo, v. 19, n.1, 1993, p. 87. Disponível em <http://www.revistas.usp.br/rfe/article/viewFile/33513/36251>. acessado em 23 de maio de 2015. 
63 ANTUNES, José Leopoldo Ferreira. Medicina, leis e moral. Pensamento médico e comportamento no Brasil (1870 - 1930). São Paulo: Editora UNESP, 1998, p. 208.

64 LUZ, Madel. Medicina e ordem política brasileira. Rio de Janeiro: Graal, 1982, p. 166. 65 PUPO, Aguiar. Uma campanha salutar: a luta contra a syphilis em São Paulo - Sobre a organização de dispensários anti-venereos e sua função prophylactica. Revista de Medicina, São Paulo, v. 003, n. 020, 1922, p. 16. Disponível em: <http://www.obrasraras.usp.br/xmlui/bitstream/handle/123456789/4157/Revista_de_Medicina_vol_3_n_20_1922.pdf?sequence=1>

66 Idem., p. 17.

67 Idem.

68 MEIRA, Rubião. Lição Inaugural. Revista de Medicina, São Paulo, v. 011, n. 046, 1927, p. 93. Disponível em: $<$ http://www.obrasraras.usp.br/xmlui/bitstream/handle/123456789/4188/ Revista_de_medicina_V_11_n_46_1927.pdf?sequence $=1>$

69 FESTIVAL beneficiente. Revista de Medicina, São Paulo, v. 013, n. 050, 1928, p. 65. Disponível em: < http://www.obrasraras.usp.br/xmlui/bitstream/handle/123456789/4191/ Revista_de_medicina_V_13_n_50_1928.pdf? sequence $=1>$

70 CARRARA, op.cit., p. 36.

71 PUPO, op.cit., p. 17.

72 BOURROUL, op.cit., p. 4.

73 PUPO, op.cit., p. 18-19.

74 Idem., p. 19.

75 Idem., p. 21.

76 A MODERNA therapeutica da syphilis e o parecer do prof Mingazzini sobre o mercurio. Revista de Medicina, São Paulo, v. 012, n. 048, 1927, p. 377. Disponível em: < http://www.obrasraras.usp.br/xmlui/bitstream/handle/123456789/4190/Revista de medicina_V_12_n_48_1927.pdf?sequence $=1>$

77 PUPO, op.cit., p. 20.

78 BOURROUL, op.cit., p. 9.

79 CARRARA, op.cit., p. 34.

80 MEIRA., op.cit., p. 31.

81 CARRARA, op.cit., p. 34.

82 CUNHA, 1941 apud CARRARA, op.cit., p. 69.

83 CAMPOS, op.cit., p. 5.

84 CARRARA, op.cit., p. 72.

85 MATOS, Maria Izilda Santos de. Construindo a paulistaneidade. As representações do feminino e do masculino no discurso médico-engênico, São Paulo (1890 - 1930). História Revista. Goiânia, v.1, n.1, 1996, p. 125.

86 SCHWARCZ, Lilia Moritz. O espetáculo das raças. Cientistas, instituições e questão racial no Brasil do século XIX. São Paulo, Companhia das Letras, 1993, p. 259. 
87 SANTOS, Luiz Antonio de Castro. O pensamento sanitarista na Primeira República: Uma ideologia de construção da nacionalidade. Dados. Revista de Ciências Sociais. Rio de Janeiro, v.28, 1985, pp. 193-210.

88 COSTA, op.cit., p. 34

89 PORTOCARRERO., V. Arquivos da loucura: Juliano Moreira e a descontinuidade histórica da psiquiatria. Rio de Janeiro: Editora FIOCRUZ, 2002, p. 87.

90 CARRARA, op.cit.

Recebido em: 01/03/2016

Aprovado em: 18/04/2017 